\section{Influenza vaccination of health care workers}

To support his argument in favour of compulsory influenza vaccination of health care workers, Flegel ${ }^{1}$ cites a Cochrane review ${ }^{2}$ as evidence of the vaccine's benefit.

However the following points should be noted:

- Flegel fails to convey to readers the Cochrane review's warning: "All findings must be interpreted with caution given the presence of selection bias."

- The author has cited the 2006 version of the Cochrane review, ${ }^{2}$ rather than the up-to-date version from $2010 .^{3}$

- The up-to-date Cochrane review from 2010 largely contradicts Flegel's statements, and suggests the evidence of benefit is poor. The reviewers write: "The three studies in the first publication of this review and the two new studies we identified in this update are all at high risk of bias." They summarize: "We conclude that there is no evidence that only vaccinating healthcare workers prevents laboratoryproven influenza, pneumonia, and death from pneumonia in elderly residents in long-term care facilities."

- Flegel also failed to cite another Cochrane review, which suggests alternatives to vaccination: "Implementing barriers to transmission, such as isolation, and hygienic measures (wearing masks, gloves and gowns) can be effective in containing respiratory virus epidemics or in hospital wards." ${ }^{4}$

These issues should be clarified and corrected.

Peter Doshi PhD, Elia Abi-Jaoude MSc MD, Joel Lexchin MD, Tom Jefferson MD MSc MRCGP, Roger E. Thomas MD PhD

Postdoctoral Fellow in Comparative Effectiveness Research, Divisions of General Pediatrics and General Internal Medicine (Doshi), Johns Hopkins University, School of Medicine, Baltimore, Md; Research Fellow, Department of Psychiatry (AbiJaoude), University of Toronto; Staff emergency physician, University Health
Network (Lexchin), Toronto, Ont.; Reviewer, Cochrane Collaboration (Jefferson), Rome, Italy; and Professor of Family Medicine (Thomas), University of Calgary, Calgary, Alta.

\section{References}

1. Flegel K. Health care workers must protect patients from influenza by taking the annual vaccine. CMAJ 2012;184:1873.

2. Thomas RE, Jefferson T, Demicheli V, et al. Influenza vaccination for healthcare workers who work with the elderly [review]. Cochrane Database Syst Rev 2006;(3):CD005187.

3. Thomas RE, Jefferson T, Lasserson TJ. Influenza vaccination for healthcare workers who work with the elderly. Cochrane Database Syst Rev [review] 2010;(2):CD005187.

4. Jefferson T, Del Mar C, Dooley L, et al. Physical interventions to interrupt or reduce the spread of respiratory viruses [review]. Cochrane Database Syst Rev 2010;(1):CD006207.

CMAJ 2013. DOI:10.1503/cmaj.113-2096

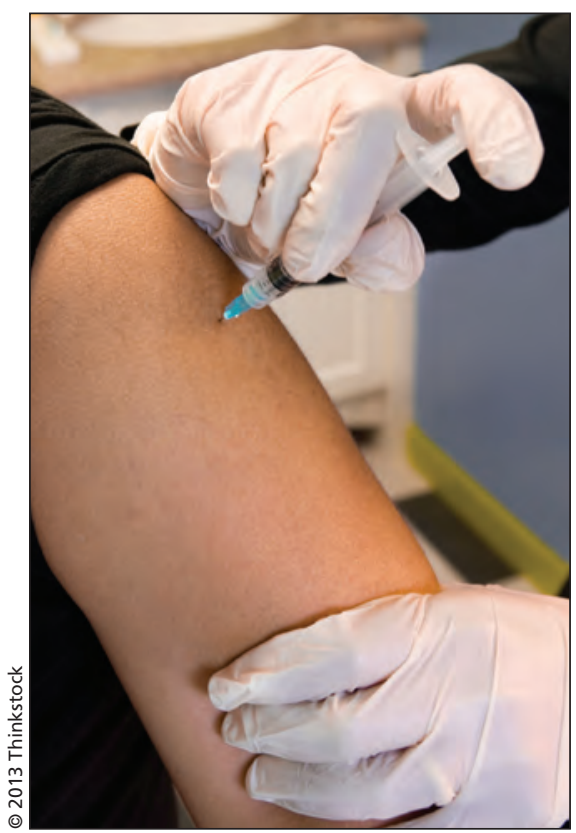

Although we strongly support increasing influenza vaccination of health care workers, we believe that guidance supporting this effort should be based on scientifically sound evidence regarding influenza vaccine effectiveness and the subsequent disease reduction in influenza workers and their patients. The editorial by Flegel contains factual errors, and the data cited to support the case for health care worker vaccination are problematic.

The vaccine efficacy rate of "about $86 \%$ when the circulating strain and vac- cine strain are well matched" is not an accurate statement, and the reference provided does not support that conclusion. ${ }^{1,2}$ We recently conducted a comprehensive meta-analysis of influenza vaccine efficacy and effectiveness and found that the trivalent inactivated vaccine provides approximately $59 \%$ protection in healthy younger adults and that match did not significantly affect how well the vaccine protected against influenza. ${ }^{3}$ Additionally, we found that the perception that current influenza vaccines provide such high levels of protection is a major barrier to developing novel-antigen, game-changing vaccines. ${ }^{4}$

Also, the 4 randomized controlled trials cited in reference 5 do not provide strong evidence to support an impact on patient mortality when increased numbers of health care workers are vaccinated. ${ }^{5}$ In fact, 2 of the studies do not support this claim, ${ }^{6,7}$ and the other 2 only weakly support it. ${ }^{8,9}$

The cost savings report cited ${ }^{10}$ (reference $^{6}$ in the editorial) uses the 2006 HICPAC statement as the source for these cost savings, but those numbers are not present in that report. ${ }^{11}$ Additionally, most cost-effectiveness numbers are based on overestimated vaccine efficacy and need to be revised. ${ }^{4}$

Last, there is no process for selecting influenza vaccine strains that reduces the risk of Guillain-Barré syndrome (GBS), as the reason influenza vaccine causes GBS is still unclear.

\section{Michael T. Osterholm PhD MPH, Nicholas S. Kelley PhD}

Center for Infectious Disease Research and Policy University of Minnesota, Minneapolis, Minn.

\section{References}

1. Flegel K. Health care workers must protect patients from influenza by taking the annual vaccine. CMAJ 2012;184:1873.

2. Thomas RE, Jefferson T, Demicheli V, et al Influenza vaccination for healthcare workers who work with the elderly [review]. Cochrane Database Syst Rev 2006;(3):CD005187.

3. Osterholm MT, Kelley NS, Sommer A, et al. Efficacy and effectiveness of influenza vaccines: a systematic review and meta- analysis. Lancet Infect Dis 2012;12:36-44.

4. Osterholm MT, Kelley NS, Manske JM, et al. The Compelling need for game-changing influenza vac cines: an analysis of the influenza vaccine enterprise and recommendations for the future. Minneapolis 
(MN): Center for Infectious Disease research \& Policy; 2012. Available: www.cidrap.umn.edu/cidrap /files/80/ccivi\%20report.pdf (accessed 2012 Oct. 31)

5. Talbot TR, Babcock H, Caplan AL, et al. Revised SHEA position paper: influenza vaccination of healthcare personnel. Infect Control Hosp Epidemiol 2010;31:987-95.

6. Potter J, Stott DJ, Roberts MA, et al. Influenza vaccination of health care workers in long-term-care hospitals reduces the mortality of elderly patients. $J$ Infect Dis 1997;175:1-6.

7. Carman WF, Elder AG, Wallace LA, et al. Effects of influenza vaccination of health-care workers on mortality of elderly people in long-term care: a randomised controlled trial. Lancet 2000;355:93-7.

8. Hayward AC, Harling R, Wetten S, et al. Effectiveness of an influenza vaccine programme for care home staff to prevent death, morbidity, and health service use among residents: cluster randomised controlled trial. BMJ 2006;333:1241.

9. Lemaitre M, Meret T, Rothan-Tondeur M, et al. Effect of influenza vaccination of nursing home staff on mortality of residents: a cluster-randomized trial. J Am Geriatr Soc 2009;57:1580-6.

10. Steckel CM. Mandatory influenza immunization for health care workers: an ethical discussion. AAOHN J 2007;55:34-9.

11. Pearson ML, Bridges C, Harper S, et al. Influenza vaccination of health-care personnel: recommendations of the Healthcare Infection Control Practices Advisory Committee (HICPAC) and the Advisory Committee on Immunization Practices (ACIP). MMWR Recomm Rep 2006;55(RR-2):1-16.

\section{CMAJ 2013. DOI:10.1503/cmaj.113-2097}

\section{The author responds}

I thank Osterholm and Kelley ${ }^{1}$ for alerting me to citation errors in my editorial. ${ }^{2}$ These errors were adopted from other influenza experts. ${ }^{3,4}$ I owe it to $C M A J$ readers to find the original evidence. My editorial was in press when the report by Osterholm and colleagues was released online. Their report provides a welcome cold shower on our former enthusiastic estimates of influenza vaccine efficacy and it highlights the need for better research on influenza-specific outcomes from immunization programs, as well as the need for a search for more effective vaccines. At the time I wrote the editorial, finding a range of estimates that included the influenza vaccine efficacy rate that I cited was relatively easy. In their report, Osterholm and colleagues note some of these older estimates. ${ }^{5}$

Doshi and colleagues concluded that there is no credible evidence that influenza vaccination prevents incident cases of influenza, particularly those cases transmitted by health care workers. ${ }^{6}$ However, the authors do acknowledge the drop in seasonal all-cause mortality seen in the 4 randomized trials discussed in my editorial. Surprisingly, the authors dismiss this evidence because of weaknesses in the trials and because they believe that there is a risk of bias and confounding. Any medical intervention that can lower all-cause mortality over the short term is impressive. Rather than dismiss this evidence outright, we need to challenge it with large, randomized controlled trials that encompass influenza-specific outcomes.

In the meantime, we are still faced with a set of inconvenient facts about the average influenza season in Canada: there are about 20000 hospital admissions; at least hundreds of Canadians die of influenza; ${ }^{5}$ and the virus circulates in our health care institutions, where the number of cases owing to shedding by health care workers, patients and visitors is not known.

Also, we have a population of increasingly elderly, sick and immunocompromised inpatients, who, once exposed, are unable to protect themselves from infection and its serious consequences. Updated estimates by Osterholm and colleagues indicate that current adult vaccines appear to be safe and to protect at least $50 \%$ of vaccinated Canadians from getting influenza. ${ }^{5}$ Although there are no good estimates of vaccine efficacy in health care workers, those who are young and healthy could presumably respond well to current vaccines. But the rate of vaccine uptake among health care workers is too low at about 40\%-50\%.

Nothing justifies our failure to improve the rates of vaccination in our health care workers. The burden of proof lies upon those against enforcement of much higher rates of adherence and on those health care workers who continue to refuse vaccination to show that they are not inflicting unnecessary harm on vulnerable patients. In the meantime, I suggest to inpatients that they ask their doctor or nurse: "Have you had your flu shot?"

\section{Ken Flegel MD}

Senior Associate Editor

CMAJ

\section{References}

1. Osterholm MT, Kelley NS. Influenza vaccination of health care workers [letter]. CMAJ 2013;185: 150-1.

2. Flegel K. Health care workers must protect patients from influenza by taking the annual vaccine. CMAJ 2012;184:1873.

3. Lam P-P, Chambers LW, Pierrynowski MacDougall DM, et al. Seasonal influenza vaccination cam- paigns for health care personnel: systematic review. CMAJ 2010;182:E542-8.

4. Steckel CM. Mandatory influenza immunization for health care workers - an ethical discussion. AAOHN J 2007;55:34-9.

5. Osterholm MT, Kelley NS, Sommer A, et al. Efficacy and effectiveness of influenza vaccines: a systematic review and meta- analysis. Lancet Infect Dis 2012;12:36-44.

6. Doshi P, Abi-Jaoude E, Lexchin J, et al. Influenza vaccination of health care workers [letter]. CMAJ 2013; $185: 150$.

CMAJ 2013. DOI:10.1503/cmaj.113-2098

\section{Missing determinant of vaccination concordance}

Quach and colleagues have formulated an interesting article on influenza vaccination coverage across ethnic groups in Canada. ${ }^{1}$ However, the authors missed perhaps the most important factor in vaccination status: length of time since one's arrival or his or her ancestors' arrival in Canada. This factor would correlate strongly with first-hand or familial experience with infectious disease in either one's country of origin in the developing world or in suboptimal conditions as a result of war, or as a refugee. Generally, people who have seen first-hand the devastating and often lethal effects of infectious disease are eager to receive vaccinations for themselves, their children and grandchildren - especially when vaccinations are without cost. Except for the Aboriginal population, which was not easily identified or measured in this study, ${ }^{1}$ white people and black people have been in Canada longer than almost every other group. They have the least experience with and memory of disease, pestilence and plague.

\section{Albert J. Schumacher MD}

Adjunct Professor Family Medicine, Western University, Windsor Ont.

\section{Reference}

1. Quach S, Hamid JS, Pereira JA, et al.; the Public Health Agency of Canada/Canadian Institutes of Health Research Influenza Research Network Vaccine Coverage Theme Group. Influenza vaccination coverage across ethnic groups in Canada. CMAJ 2012;184:1673-81.

CMAJ 2013. DOI:10.1503/cmaj.113-2099

Some letters have been abbreviated for print. See www.cmaj.ca for full versions and competing interests. 